\title{
Observing Supreme Court Oral Argument: A Biosocial Approach
}

\author{
James N. Schubert Northern Illinois University, USA \\ Steven A. Peterson Alfred University, USA \\ Glendon Schubert University of Hawaii/Southern Illinois University, USA \\ Stephen Wasby State University of New York at Albany, USA
}

\begin{abstract}
Supreme Court oral argument (OA) is one of many face-to-face settings of political interaction. This article describes a methodology for the systematic observation and measurement of behavior in $O A$ developed in a study of over 300 randomly selected cases from the 1969-1981 terms of the U.S. Supreme Court. Five sources of observation are integrated into the $\mathrm{OA}$ database at the speaking turn level of analysis: the actual text of verbal behavior; categorical behavior codes; aspects of language use and speech behavior events; electro-acoustical measurement of voice quality; and content analysis of subject matter. Preliminary data are presented to illustrate the methodology and its application to theoretical concerns of the research project.
\end{abstract}

James N. Schubert is Professor of Political Science and Director of the Program for Biosocial Research, Social Science Research Institute, Northern Illinois University, DeKalb, IL 60115-2854, USA.. He is currently serving as Executive Director of the Association for Politics and the Life Sciences and as Editor of the Newsletter of the American Political Science Association's Organized Section for Politics and the Life Sciences. Steven A. Peterson, who has published on a wide variety of topics in biopolitics and political behavior, is Professor of Political Science at Alfred University. Glendon Schubert, Professor of Political Science at the University of Hawaii, is a long-time and prolific student of judicial politics, constitutional law, and biopolitics. Stephen Wasby is Professor of Political Science at the State University of New York at Albany. His career has been devoted to the study of public law and judicial politics.
A SUBSTANTIAL AMOUNT of political behavior occurs through face-to-face interaction. The face-to-face setting is present when small groups meet, when candidates face off in debates, and when lawyers negotiate in the corridors of courthouses (Dorff and Steiner, 1981; Nardulli, Flemming and Eisenstein, 1984). The face-to-face setting cuts across levels of government from municipal councils to international summit meetings. It also cuts across time; the face-to-face setting was no doubt even more common in politics 50,000 years ago than it is today. Although a substantial proportion of face-to-face interactions is not accessible to political researchers, another substantial proportion is. Indeed, there is a rapidly expanding wealth of raw political data stored on videotape, awaiting the attention and curiosity of political scientists. ${ }^{1}$

Advances in video recording and microcomputing technology have made the concept of systematic observation of face-to-face politics more physically practical and financially feasible for political researchers (J. N. Schubert, 1988). In contrast with other scientific disciplines in and out of the social sciences, political science has no tradition of direct, observational field research. A few political scientists, however, have begun to apply the theoretical and methodological approach of human ethology in observational studies of politics (Watts, 1981; J. N. Schubert, 1983; Barner-Barry, 1986; G. Schubert and Masters, 1991). In his Presidential Address to the American Political Science Association (APSA)

Acknowledgements Earlier versions of this article were presented at the Conference on Empirical Biopolitics held at Alfred University in July, 1990 and the 1990 Annual Meeting of the American Political Science Association, San Francisco. The research upon which this article is based is supported by a grant from the U.S. National Science Foundation (SES-8900171), "The Role of Oral Argument in Supreme Court Decision Making." 
more than a decade ago, John Wahlke (1979) critiqued the pre-behavioral methodology of survey- and interview-based research and called for a more behavioral political science based on observation of actual political behavior. Although inspired by a different concept of observation, Richard Fenno (1986) likewise utilized the occasion of his APSA Presidential Address to urge more observation-based political research. This article presents and illustrates a methodology for the observation and measurement of interactive political behavior in U.S. Supreme Court oral argument that might be adapted for use in other face-to-face political settings.

Oral argument (OA) is a variant form of a common setting in politics that involves questioning of an individual by a panel or committee. Interrogative situations occur in legislative committees, boards, councils, and federal and state appellate courts. They offer possibilities for exploring a rich and diverse set of theoretical questions. Role behavior (Watson and Stookey, 1988), leadership and influence, coalition strategies, competition, and conflict behavior are among the obvious dependent variables (Barber, 1966). In addition to providing data about the actual behavior of groups in public, observational research can provide the basis for insights and inferences about the behavior of groups in private.

Audio tapes and printed transcripts are now available through the U.S. National Archives for almost all OAs of the Supreme Court since the beginning of the Burger Court and for many Warren Court cases as well. The methods we describe for the observation and measurement of behavior are based upon the availability of audio tapes and transcripts. If we were studying state appellate courts, our methodology would be expanded to take advantage of videotape recordings of proceedings. The methods described below are being applied in a study of the U.S. Supreme Court's OA in 318 cases sampled from the 1969-81 terms. Because the purpose of this article is to describe and illustrate a methodology for observation and measurement, we do not report generalizable findings about Supreme Court oral argument, nor test theoretically based hypotheses. ${ }^{2}$ Instead, our objectives are twofold. One is to describe and explain a biobehavioral methodology that underlies a series of theoretically focused research reports, as well as the OA database that will be archived with the Inter-University Consortium for Political and Social Research (ICPSR) to permit secondary analyses. The second objective is to make our methods widely available to other scholars in biopolitics, both for critique and for adaptation to other research problems.

\section{Oral argument in court decision-making}

Despite abundant evidence that participant judges and attorneys consider oral argument to play an important role in appellate court decision-making, there has been almost no behavioral research on $\mathrm{OA}$ in political science, even for the United States Supreme Court (with the notable exception of McFeeley and Ault, 1979).

The absence of research on OA leaves a gap in our understanding of the process of Supreme Court decision-making. Although estimates of the importance of this gap are conjectural, the perceptions of participants in OA (Harlan, 1955) and other informed observers of appellate courts are that OA serves a variety of important functions in the judicial decision-making process (Howard, 1981; Wasby, 1981; Chapper, 1983).

\section{The role of $O A$}

Basic functions of OA have been discussed by legal scholars in great detail, and these purported functions illustrate the importance associated with OA (Chapper, 1983; Shapiro, 1984; Wasby, 1981, 1982). In this literature, authors propose that, for the Justices and the Court, OA

- clarifies the nature of the issues involved in a case;

- clarifies the logic of claims made in a case;

- allows Justices to try to persuade one another;

- legitimatizes the legal process by indicating that the Justices seriously listen to arguments;

- enhances communication between judges and lawyers;

- permits Justices to try out arguments for use in opinions;

- enhances collective consideration of issues by the Justices; and

- focuses attention on the issues over which the Justices disagree.

For counsel, these studies propose that OA

- allows lawyers to persuade Justices of the correctness of their claims;

- can motivate a Justice to view a lawyer's case more positively;

- shows clients that their lawyers have gotten the Supreme Court to listen to their arguments; and

- clarifies for lawyers the focus of the case in the eyes of the Justices.

OA represents one of the two contexts in which the Court functions face-to-face. Although we must still depend on personal papers to gain direct insight into social interaction patterns in conference, interactions are, and have always potentially been, directly observable in OA. The importance of interaction patterns for appellate court decision-making is indicated in descriptive and empirical studies (Howard, 1968; Murphy, 1966; Ulmer, 1981). A study of the Swiss Federal Tribunal, based on 
direct observation of interactions among judges, analyzed the effects of interactions on outcomes (G. Schubert, 1985). The Tribunal's judges discuss cases in public session and reach decisions openly. Such variables as arousal level (energy mobilization, excitation, agitation, increased attentiveness) and emotionality of speaking judges were found to affect interactions among the judges, as well as their voting behavior. Interaction processes and the emotions tied to them are key factors, according to this study, in understanding outcomes.

In his study of the Swiss Federal Tribunal, Glendon Schubert postulates as conventional a linear causal structure within which interactions affect decisions:

\section{ATTRIBUTES $\rightarrow$ STRUCTURES $\rightarrow$ INTERACTIONS $\rightarrow$ DECISIONS.}

Attributes include background variables, and structural variables include political attitudes and aspects of social structure on a court. Interactions, of course, occur at various points and through different means in the $\mathrm{Su}$ preme Court's decision process, and OA is only one context of interaction. In general, we are concerned with how judicial attributes, ideology, and structural properties of group membership affect interactive behavior and with how interaction may affect decisions. Thus, properties of oral argument are theoretically important as both dependent and independent variables. As dependent variables, observations of OA provide direct behavioral data on Justices, enabling explanation of judicial behavior. As independent variables, observations on OA permit analyses exploring the contribution of $\mathrm{OA}$ to outcomes-votes, opinions, dissents, and concurrences.

\section{Theoretical bases}

Systematic observation and measurement do not occur in a theoretical vacuum. The aspects of OA that our methods are designed to measure are selected on the basis of assumptions and hypotheses about when and how OA may be important in Supreme Court decisionmaking. The potential for OA to have important effects is clearly greatest when one or more Justices have not made up their minds prior to argument. For the undecided, argument provides opportunities to clarify uncertainties and for persuasion by counsel or other Justices. Uncertainties might arise from the complexity of the legal questions in a case, the novelty of the issues, value conflicts, or even the inexperience of the Justices (a newcomer or "freshman" effect). However, even when Justices attend argument with a relatively firm disposition toward a case, they may be susceptible to compromise to enable consensus formation; or they may change their perceptions of factual matters as a consequence of exposure to OA (Wasby et al, 1991).

These are among the factors that Howard (1968) proposed to explain "fluidity" in judicial voting. The

\section{Oral argument consists primarily of remarks prepared by counsel prior to the session and interactions between Justices and counsel dealing with specific topics}

variability that Brenner (1980) and Brenner and Spaeth (1986) observe between conference and final votes indicates that Justices often do change their minds (and see Schwartz, 1985, 1988). Flexibility may be even greater prior to taking a formal stance in conference voting. Drawing upon the literature on functions of OA, we are interested in the opportunity that OA provides for persuasion and clarification to affect Justices' attitudes towards cases.

Behavior that addresses the functions of persuasion and clarification reflects underlying psychophysiological states. Thus, behavior seeking clarification from counsel presumably is caused by cognitive uncertainty, whereas persuasive behavior may express underlying emotional bases of interest, commitment, and arousal. Of course, we cannot learn directly from OA about the feelings of Justices who do not participate in it. However, we may infer a lower level of interest in a case from nonparticipation, especially when it represents a statistically significant difference from normal individual behavior.

In addition to our interests in the "how" and "why" aspects of judicial participation in $\mathrm{OA}$, we are also interested in the "what"-the subject matter or substantive content of behavior. What do Justices ask questions about? What is oral argument about in terms of facts, legal matters, issues, doctrine, precedents, values, etc.? Justices seek clarification or attempt to persuade in relation to issues, laws, doctrines, facts, and values. Emotions and uncertainties have their referents in the actual stimuli present in a case.

To complement our interests in the importance of OA for Supreme Court decision-making and how Justices in general use this time, we are also interested in roles assumed by Justices in the conduct of OA. Who leads, who follows, and under what conditions do different Justices assume different roles? Specifically, we are interested in task leadership (Bales, 1950; Ulmer, 1981) and how the agenda of issue consideration is shaped by the behavior of participants.

\section{The setting of $O A$}

To understand the possibilities for observation and measurement, it is necessary to consider briefly the nature of OA in the Supreme Court. The actors include the 
Table 1. Variables describing speaking turns in Oral Argument

Variable

\section{Identifing properties \\ Case ID \\ Turn sequence number \\ Speaker \\ Party \\ Length \\ Interjections \\ Interruptions}

\section{Grammatical Form}

Argumentation Role

Intention

Affect

Arousal

Pitch

Pitch Range

Pitch Variability

Intensity

Speech Rate

Uncertainty

\section{Verbal Display \\ Affect \\ Agreement}

Verbal Content

Issue

Base

Legal Concept

Role

Value

Valence

\section{Definition}

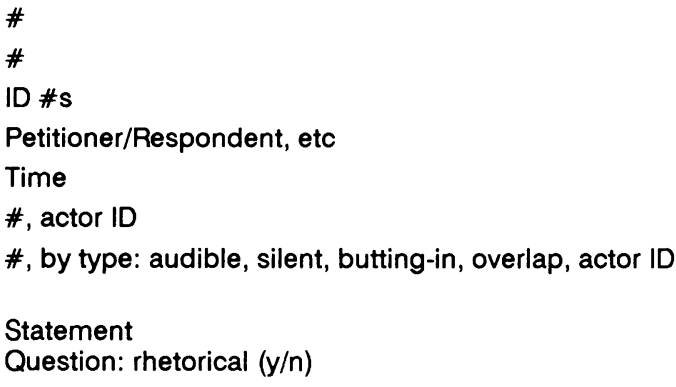

Origination: (begins new line of questioning/interaction)

Subject shift: (within existing line of questioning)

Follow-up/reaction: repetition/rephrasal/neither (iterates, reiterates, or rephrases question)

$$
\begin{array}{ll}
\text { Procedural: } & \text { pertaining to } O A \\
\text { Factual: } & \begin{array}{l}
\text { questions of fact, case record, etc } \\
\text { meaning (clarification of counsel's argument) } \\
\text { mixed (meaning and validity) } \\
\text { validity (evaluates counsel's argument) }
\end{array} \\
\text { Other } &
\end{array}
$$

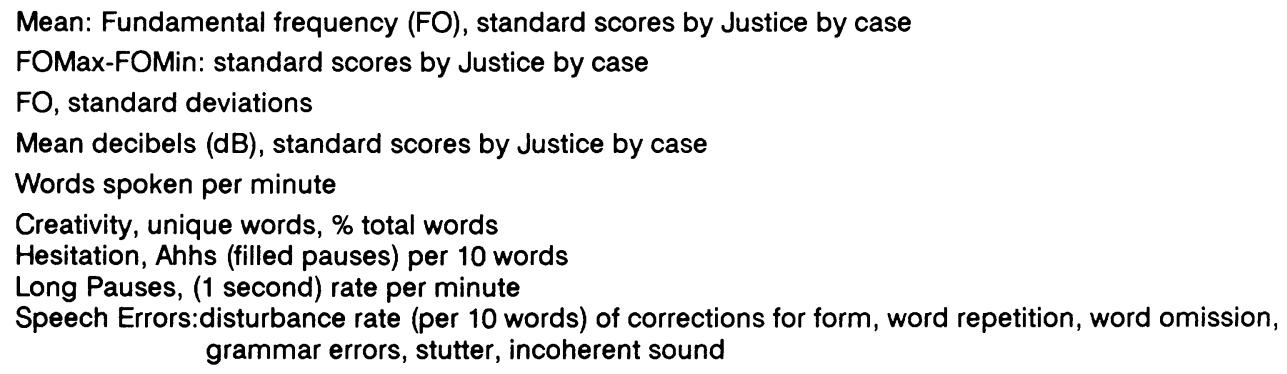

Positive (praise, flattery)/Negative (sarcasm, irritation, etc)

Agreement/Disagreement

\author{
category codes adapted from NSF Judicial Data Base \\ category codes adapted from NSF Judicial Data Base \\ precedent cases, doctrines, tests, etc. \\ References to persons in role (parties, counsel, Justices, etc.) \\ political liberalism, economic egalitarianism, federalism, judicial centralization \\ $(+/ 0 /-)$ affective valence modifies all content variable codes
}

Note: $\quad F O=$ fundamental frequency, $\mathrm{dB}=$ decibels

Justices and two or more attorneys. Attorneys come with prepared presentations; and their time, usually 30 minutes for each side, begins with a monologue, although it may last less than a minute as Justices interrupt the speaking attorney at will. An interrupting question opens a question/answer sequence that may include a number of exchanges on a topic with any number of Justices joining in the interaction. At the end of a topical sequence of interactions, the attorney may resume (or attempt to resume) the formal presentation; or a Justice may introduce a new topical area for discussion. Thus, an oral argument consists primarily of remarks prepared by counsel prior to the session and interactions between Justices and counsel dealing with specific topics. Otherwise, verbal behavior is concerned with procedural matters, especially the allocation of time, and social relations-personal recognition and, occasionally, humor. 
The selection of methods for observation and measurement is affected by constraints both in the structure and in the content of interactions in OA. Justices effectively control the topical flow, in a sense picking and choosing from the menu of issue options provided by the attorneys, the briefs, and their own interests. Structurally, the interpersonal flow of interaction is between Justices and counsel. Rarely do the Justices directly, formally interact with one another (Wasby, D'Amato, and Metrailer, 1976). This is not to suggest that the Justices do not interact, even debate points, but that discussion and argumentation between Justices occurs through the medium of the Justice-counsel dyad. Therefore, our methodology is based primarily upon observation of interactions between Justices and counsel. One implication of this structure of interaction is that established methods for studying small group interactions, such as Bales's (1950) Interaction Process Analysis, cannot be applied without substantial modification.

In content and substance, the interactions between Justices and counsel, unlike most other forms of conversational interaction, are narrowly focused upon the case-as argued by counsel, as presented in the briefs, and as otherwise perceived by the Justices. In this context, judicial behavior is essentially limited to questions of counsel that address matters of fact and the logic of arguments pertaining to a case. An important methodological implication of this substantive constraint is that there is a limit to the range of natural variation in the types of behavior that occur in OA and that might be observed and measured. The range that might be encountered in a legislative committee or city council is potentially much broader.

Typically, questions in OA are short and direct, averaging about four seconds in length. In a study based on printed transcripts of all cases argued in the 1980 and 1981 terms $(\mathrm{N}=281)$, J. N. Schubert (1990) reports substantial variation across cases in the amount of questioning by Justices. The amount of text in the transcripts associated with speech by the Court had a mean of $27 \%$ with a standard deviation of 7 . For a 60 -minute argument, a one standard deviation range indicates that from 12 to 20 minutes of judicial speech is common. In an OA with active participation by Justices, there might be more than 150 separate questions. Thus, a single OA may yield a substantial amount of observational data.

\section{Observation and measurement}

Table 1 provides a summary of the properties of OA on which we have recorded observations. In general, the speaking turn, defined as the period in which a speaker holds the floor, is the unit for direct observation and measurement. The first set of variables includes physical and identifying properties of turns: sequence, speaker, and length. To develop these data, (1) the official printed transcripts are corrected from the audio recording, (2) speaking turns are denoted on the transcripts, (3) turns are timed with a stop watch from the audio tape, and (4) speakers are identified by voice (because they are not identified in official transcripts available from the Supreme Court Library or from the National Archives). Official transcripts of OA contain many errors, including both omitted speech and incorrect transcription, and correction is an important, albeit time-consuming, task.

To facilitate accurate identification of speakers, sample segments of speech for each Justice were made available to coders on tape. These samples are taken from situations during arguments in which Justices were referred to by name, either by counsel or other Justices. Coders were trained to recognize voices from these tapes and to refer to them for voice comparisons, as necessary. Some Justices have similar voices, and identification errors are likely to be concentrated among them. White, Stewart, and Stevens were somewhat more difficult to distinguish, while Burger, Rehnquist, Marshall, O’Connor, and Powell were the easiest. Errors are also more common for brief, one- or two-word utterances. Nevertheless, intercoder agreement in speaker recognition from voice on OA tapes for trained coders is above $90 \%$ per case.

A second set of variables addresses our theoretical concerns with roles and intentions in behavior. Argumentation role is a variable that locates a turn in the sequence of interactions. It describes whether an utterance by a Justice begins a sequence of interactions on a new subject or continues an existing one. Specifically, this variable distinguishes between originating utterances that introduce new topics (Mazur and Cataldo, 1989) and those that follow up or are reactive in the sequence of exchange. Among originating utterances, coders distinguish those that commence a topically new line of questioning - usually when a Justice interrupts a period of monologue by counsel - and those that introduce a subject shift within an existing topic of interaction. The distinction is important, among other reasons, because utterances that "originate" provide direction in the overall argument, defining the agenda of issue consideration. For instance, in a series of interactions between Fried and Kennedy/O'Connor, in Webster over the issue of a "right to procreate," O'Connor introduced a subject shift with a hypothetical question regarding the state's right to require abortion as a population control measure.

Utterances that are reactive or pose follow-up questions are also coded for rephrasal or verbatim repetition. Repetitious questioning is indicative of Justices' interest in a topic and, often, of dissatisfaction with answers provided by counsel.

The categories of intention distinguish among acts 
that are "procedural," regulating the argument itself, those that establish "facts," and those that address the "logic of the argument" presented by counsel or in the briefs. Most procedural comments announce the turns, identity, and time remaining for counsel. Almost all of these comments are by the Chief Justice, and the procedural code is used to distinguish nonprocedural acts by the Chief in behavioral comparisons with other Justices. The factual category is coded for behavior that involves facts of the case, case materials (what is in the briefs), and the history of the case in lower courts. Apart from procedural and factual matters (or occasional humor and other social behavior), Justices' questions address the (1) meaning and/or (2) validity or acceptability of an attorney's argument.

Questions of "meaning" may be concerned with understanding the words spoken by counsel-when the attorney misspeaks, when noise interferes with a Justices's hearing, when a Justice has had a lapse of attention, or when a Justice wants confirmation that he has correctly heard and understood the attorney. Alternatively, Justices may wish to clarify a specific argument or consider the implications of the argument that has been expressed by counsel or that appeared in the briefs. For example, Stevens asked Webster in the Webster OA (NYT, 1989, Webster v. Reproductive Health Services, OA April 26, 1989), "Let me be sure I understand. You are saying the doctor, if he thinks it is unnecessary, doesn't have to perform the lung test?"

Not infrequently, Justices explicitly ask counsel for an opinion or interpretation. Thus, O'Connor asked of Webster, "Do you say there is no fundamental right to decide whether to have a child or not?" Coders are instructed to use this category when Justices act to increase their understanding of the issues, claims, and interpretations in the positions presented and represented by counsel. Other questions that have a nominally objective form but ask for interpretation by counsel are coded as addressing "meaning," not fact. Thus, the question, "What is the right involved in Griswold?" asked counsel for an interpretive response (and Webster provided one); this question would properly be coded as addressing meaning.

Some utterances by Justices, especially statements, are argumentative and challenge the "validity" of the argument by counsel. In Webster, Rehnquist took exception to a claim in Sussman's argument, "If you say there is a deeply rooted tradition of freedom in this area, that suggests that there had been no legislative intervention to me. What you are, that simply is not the fact." In another example, Scalia originated a sequence of interaction with a challenge to the validity of Sussman's argument, "Excuse me, you find it hard to draw a line between those two [cases: Griswold and Roe] but easy to draw a line between first, second and third trimester ... I I don't see why a court that can draw that line can't separate abortion from birth control quite readily."

In some instances the distinction between seeking clarification and challenging validity is clear, while in others it is not. One situation of ambiguity occurs when the challenge is conveyed through intonation rather than words. Thus, an utterance that begins, "Do you mean to say ...," would, on the basis of verbal content, be coded as a query for "meaning." However, if the emphasis in speaking is on the "you" and "mean" rather than on the "Do" and "say," a request for clarification becomes an expression of incredulity, challenging validity. Coders are provided with a "mixed" category to account for this situation. Complex utterances that include phrasing that addresses meaning as well as presenting a challenge to validity are given the validity code. Not all utterances that address the validity of argument are oppositional or pose challenges. Justices occasionally ask questions or contribute statements in support of a particular argument. Therefore, codes for "validity" are also recorded as pro or con counsel's argument.

The process of coding these data proceeds with a coder reading from a corrected transcript while listening to the audio tape for each speaking turn by a Justice and entering responses for these questions to prompts on a computer screen. The reliability of these data is discussed in the Appendix.

\section{Affect}

Our approach to measuring affect in judicial behavior during $O A$ includes attention to the feelings, opinions, and values expressed in verbal behavior and to emotion revealed during the act of speaking. It is possible to observe and measure emotion in speech behavior because the psychophysiology of emotion affects thinking-including the cognitive construction of verbal sequences expressed in speech-and the operation of the musculature utilized in vocalization.

Arousal is a physiological aspect of emotion in which the body prepares to respond to environmental stimuli (Gray, 1982; Marcus, 1988). Arousal is caused by the release of neurohormones that create conditions of alertness and attentiveness in actors. When people are speaking, arousal is communicated nonverbally through voice quality. A substantial body of empirical research reveals "strong convergence" in replicated findings (Scherer, 1986) that arousal is associated with higher pitched, louder, and faster speech. Thus, indicators of arousal are provided by measures of fundamental frequency (F0) for voice pitch, decibels (dB) of sound pressure for voice intensity or loudness (Baken, 1987), and words per minute for speech rate or tempo.

Uncertainty is a condition that affects grammatical construction, fluency, and disturbances in speech per- 
formance. "Grammatical form" is important as a verbal indicator of cognitive states. Uncertainty is commonly expressed in the interrogative, although not all questions express uncertainty. In contrast, declarative behavior often expresses certainty and may have a persuasive effect as well, although certainty is not always expressed in the declarative mode. Grammar provides an indicator, not a measure, of cognitive states. In OA, statements by Justices do frequently express unequivocal opinions to counsel that are also heard by other Justices. Questions are used both to inquire of and to challenge counsel, and Justices may display idiosyncratic patterns of grammatical construction in their interactions.

Examples of expressed certainty are found in Scalia's declarative utterances in the OA of the Webster abortion case. Scalia interrupted Webster (appellant's counsel) on the subject of fetal viability tests, "Could I interrupt for a minute? It is not just age and weight, as you mention, but also lung maturity." Webster answered, "There are three facts," and Scalia continued, "And there is a good deal of evidence that that is, number one, useless information and, number two, very difficult to find without some risk to the pregnant woman." Uncertainty about the logic of the argument is often cued with the opening language of a question: "in other words ...," "when you say ... you mean ...," "do you claim that ...," and "let me get this straight. I thought you said ...."

Anxiety is one cause of uncertainty that is postulated to have inhibitory neurochemical effects on cognitive processes that interfere with the construction and delivery of verbal messages (Siegman, 1978; Gray, 1982). Whatever the source of stress (confusion, value conflict, threat, unfamiliar stimuli, etc.), the effects of uncertainty are to degrade performance in verbal construction and speech delivery, including more frequent "long" pauses during speech, more frequent filled pauses or "ahhs," and less creative word selection - percentage of unique words (Hermann, 1977; Frank, 1977). Fluency is also affected by speech errors, such as word omissions, grammatical corrections, uncorrected grammaticai errors, word repetitions, stutters, and incoherent vocalizations that are indicative of cognitive inhibitions. In general, speech errors were far more common for counsel than Justices (J. N. Schubert, 1987). Of course, counsel are, by definition, in a stressful situation; and we would expect stress/anxiety reactions to be displayed in their speech. Complementary verbal data on uncertainty are provided by usage of such words as "guess," "maybe," and "perhaps."

In sum, we apply a multiple indicator strategy to assess uncertainty, including: (1) creativity in word selection, also known as the type-token ratio (unique words, percentage total); (2) efficiency in word selection, indicated by long pause and "ahh" or filled pause rates; (3) accuracy in language use and sound production, indi- cated by speech error rates; (4) frequency of words expressing uncertainty; and (5) grammatical construction.

Data on voice quality are developed by processing the audio tapes through electro-acoustical equipment-a VisiPitch 6087 with computer interface. An operator plays up to a nine-second segment of speech, guided by the written transcript, and a trace is displayed for pitch and loudness on the computer screen. Noting points along the trace corresponding to the beginning and end of the utterance, or portion thereof, markers are set on the screen and summary statistics extracted by the computer software.

Data on speech events are developed as coders listen to the audio tapes of OA and correct the printed transcript. They note and code relevant speech eventspauses, interruptions, speaking errors-on the transcripts at the corresponding point of occurrence on the audio recording, and they correct any mistakes in the official transcripts. Where the quality of the copy permits, transcripts are converted to word-processing text files by using optical scanning equipment with characterrecognition software. Speech event codes and corrections are then entered into the transcript files. A computer program reads each transcript, turn by turn, word by word, counting frequencies for speech event variables and writing out totals for each turn to a data file.

The positive or negative valence of affect expression is also observed. The direct verbal expression by Justices of agreement or disagreement with counsel is coded. Statements that literally express an attitude - "I disagree ... ," or, as in Rehnquist's comment in Webster cited above, "that simply is not the fact"-or those that implicitly agree or disagree with counsel, are recorded. On occasion, the expression will be directed at the prior comment of another Justice. To account for the object of the expression, whenever agreement/disagreement is coded, the ID of the object of the expression is also noted.

In addition to agreement/disagreement, extra-verbal strategies of emotional expression are observed. Negative affect is expressed when speakers use sarcasm, ridicule, or invective. Negative affect is also expressed when speakers display annoyance, irritation, and hostility in their selection of words and/or intonation. Vocal cues to irritability, in particular, are found in "harsh voice," as defined acoustically by low pitch with high pitch perturbation-or voice stress (Scherer, 1986). Positive affect is expressed through praise and flattery. Coders record these forms of positive and negative emotional expression, along with an adjective indicating the basis for the code. In practice, positive emotion appears rarely expressed in OA by Justices. In preliminary data on seven cases that included 41 total questions with codes for negative affect, 11 were based on sarcasm, 8 on ridicule, and 20 on irritation or annoyance. 


\section{Content}

The measurement model described below is designed for coding the subject matter or content of oral argument. The purpose of this scheme is to observe systematically, but parsimoniously, what Justices and counsel talk about in OA. Although described in terms of coding the subject matter of OA, the same observational approach is also applied to the text of the written opinions of a case-including dissenting and concurring, as well as majority opinions. This common approach to measuring the content of spoken and written legal discourse allows analysis of continuities in OA and Justices' formal opinions.

At any given point in time, the subject of argumentation may focus upon one or more (in combination) of the following: (1) an issue, such as due process; (2) the legal basis of a case or claim, for instance, in constitutional or statute law; (3) a legal doctrine, such as stare decisis; (4) persons/parties affected by or involved in the case or decision-making; and/or (5) the expression of political values or preferences. Anywhere within one actor's speaking turn (complete turn, sentence, phrase, word) in the argument, verbal content may address one or more of these five subjects; indeed, the same utterance may involve more than one subject. Thus, in an obscenity case, some utterances may deal with the issue of obscenity and the legal basis of its protection under the First Amendment. Unlike the data discussed above, which are observed at the level of the turn, these codes may apply to a single word.

References to subjects are often modified by affect displays. Such affect might be displayed by modifying adjectives, by intonation, or by the broader linguistic context of the subject reference. Therefore, in addition to the turn level affect data described above, all specific subject references coded on these five dimensions are also observed for affective valence, as positive, neutral, or negative.

Procedurally, coders record observations directly on the double-spaced, typewritten transcript of OA, underlining the words described by the codes, and placing the codes in direct proximity to the relevant portion of text. Thus, all codes can be checked for accuracy and are readily subject to replication.

Our approach to coding issues is borrowed from that developed in the NSF Supreme Court Judicial Data Base-Field 24, ISSUE (Spaeth, 1991). With some modifications, the numeric codes described in the coding manual for that study are used here. The purpose of this variable is to code the subject matter of comments that address the issues under contention, as opposed, for instance, to the legal basis of claims. Issue areas might involve a classification of materials as obscene; a type of crime, such as bank robbery; an event, such as a loyalty oath; or the treatment of social groupings, such as Native Americans, the handicapped, or juveniles. Issue codes are organized into 13 major groupings, such as criminal procedure (codes 010 to 199) or due process (500 to 529). For instance, individual categories in the criminal procedure area include " 010 " involuntary confession, " 014 " plea bargaining, "022" Miranda warnings, and "070" double jeopardy.

Legal base or provision is another variable operationalized following the approach of the NSF Judicial Data Base (Field 21 LAW). It describes references to the bases in constitutional or statute law, treaties, court rules, or government regulations of the matters under consideration during an argument. Constitutional code categories are identified by amendment number and issue label (e.g., "1ASN" = First Amendment, association), or by article, section, and paragraph numbers (e.g., "1101" = contract clause). Frequently litigated statutes have individual codes preassigned. References to legal bases are coded whenever they appear in an utterance.

The legal concept variable refers to doctrines, precedents, tests, and other legal concepts that may be followed or applied by the Court in its deliberations. A list of the categories provided to coders follows; but these categories are not exhaustive, and coders are instructed to supply new categories as they emerge in the arguments or opinions. Concept categories include the following: precedent cases [with label], stare decisis, res judicata, ratio decidendum/dictum, vagueness, respondeat superior, lenity, tests [ID in margin], criteria [with label: e.g., "beyond reasonable doubt" or "clear and convincing," etc.], other [with label].

A role is coded whenever expressions are about other persons. Persons involved in cases include litigants, counsel, courts, jurors, and witnesses, among others. References to people filling roles in other institutions and structures, including Congress, the President, and administrative departments, are also coded. In coding role references, the names of persons are identified, as appropriate. Role codes include U.S. Supreme Court, Justices, OA counsel, OA parties, amicus curiae, lower courts and judges in the case, lower courts and judges in other cases, other counsel, witnesses/experts, jurors, former Justices, Congress, President, administration (department, office, agency), and other.

Finally, utterances are coded for direct expression of political values. The inclusion of a values dimension in this content-coding scheme is based on the welldeveloped literature on judicial ideology (G. Schubert, 1974). The value categories coded for OA and for language in opinions encompasses the major and minor attitude scales analyzed in the body of research based on judicial voting behavior. However, because we are directly observing value expressions in judicial behavior, and also because times have changed, our categories are not limited to scales that have been extracted, validated, and replicated in judicial decision-making studies.

The political values coded include a set of 11 cat- 
egories describing attitudes of political liberalism/conservatism, 13 categories addressing problems of economic egalitarianism/conservatism, and 4 others primarily concerned with the centralization of political power. Codes identify the specific category and its associated affective valence. The political liberalism/conservatism categories include freedom of communication, fair procedure, right of privacy, political equality, racial equality, sexual equality, age equality, political freedom, religious freedom, sexual freedom, and separation of church and state. The economic egalitarianism/conservatism categories include anti-monopoly, laissez faire, (regulation of) private property, federal regulation, state regulation, union, worker, subordinate, debtor, have-not (pauper), environment, affirmative action, and public interest. Finally, the judicial and federal centralization categories include judicial activism, judicial centralization, federal centralization, and federal taxation.

The subject variables of issue, base, concept, and role have objective definitions and require inferential judgment by coders only in the assignment of a valence code. Value codes do require inferential judgments in many instances. Value codes tend to complement other codes and to describe the content of longer utterances, in contrast to the one- or two-word references indicating a code for one of the other variables. As noted above, coding is based upon both printed and audio sources, and codes are entered on the transcript adjacent to the underlined text to enable precise reliability analyses. For computer entry, each code is identified in relation to the transcript page and line numbers, speaking turn number, the type of variable, affective valence, and category code. Coding is performed by either law school students or graduate students with a concentration in public law. All of their codes are checked by a project investigator. Reliability for these data is discussed in the Appendix.

The same variables and observational approach used in coding oral argument are applied to opinions. Opinions are read, after the OA is completed, and coded in the margins, line by line. Accompanying text is underlined and associated with sequential paragraph numbers for identification of location. Majority, concurring, and dissenting opinions are treated as separate units and sequentially coded.

\section{Illustrative applications}

The application of the methodological approach in the data development process is continuing. Because many data development tasks are interdependent, progress is uneven in the extent to which even preliminary data are ready for analysis. The purpose of the discussion below is to illustrate patterns in the data that are available, especially as they bear upon the problem of validity.

Table 2 displays descriptive data on Justices' partici-
Table 2. Distributional patterns in Justices' questions

\begin{tabular}{|c|c|}
\hline Variable category & $\%$ \\
\hline \multicolumn{2}{|c|}{ Grammatical form $(N=1198)$} \\
\hline Question & 76 \\
\hline Statement & 24 \\
\hline Total & 100 \\
\hline \multicolumn{2}{|c|}{ Argumentation role $(\mathrm{N}=1198)$} \\
\hline Origination & 24 \\
\hline Subject shift & 19 \\
\hline Reaction/follow-up & 56 \\
\hline Total & 99 \\
\hline \multicolumn{2}{|c|}{ Speaker's intention $(N=1298)^{\star}$} \\
\hline Procedural & 7 \\
\hline Factual & 16 \\
\hline \multicolumn{2}{|l|}{ Argument } \\
\hline Meaning & 40 \\
\hline Mixed & 7 \\
\hline Validity & 25 \\
\hline Other & 5 \\
\hline Total & 100 \\
\hline
\end{tabular}

pation. These data show that most of the participatory utterances by Justices are structured as questions and that, in terms of argumentation role, much of this behavior is focused upon a limited number of topic areas. Indeed, 56\% of Justices' behavior follows up on or reacts within existing lines of questioning. In addition, most of the behavior addresses the logic of argument by counsel, as opposed to matters of fact. It is intriguing that roughly one-third of all Justices' turns were coded as addressing the validity of the argument (validity plus mixed). In other words, persuasive behavior is an important component of OA. The importance of the "clarification" function of $\mathrm{OA}$ is also indicated by the $40 \%$ of turns addressing "meaning" in the argument by counsel. Factual aspects of cases are relatively minor concerns in OA.

Table 3 presents crosstabulations of these data that bear on questions of concurrent validity. Assuming that statements are more assertive in form than questions, it is consistent that $30 \%$ more of the turns addressing validity were uittered as statements than were turns addressing meaning. Conversely, when Justices seek clarification due to uncertainty, we would expect to observe the interrogative form; fully $88 \%$ of the turns addressing "meaning" were phrased as questions. Considering argumentation role, it would be expected that behavior that challenges the validity of an argument is often reactive or follows up within a pattern of interaction; and the data show that $71 \%$ of the turns coded for validity 
Table 3. Intention, grammatical form, and role in questioning behavior

\begin{tabular}{|c|c|c|c|c|c|}
\hline \multirow{3}{*}{ Grammatical form } & \multicolumn{5}{|c|}{ Intention } \\
\hline & Factual & Meaning & Mixed & Validity & Other \\
\hline & $\%$ & $\%$ & $\%$ & $\%$ & $\%$ \\
\hline Question & 85 & 88 & 74 & 58 & 26 \\
\hline Statement & 15 & 12 & 26 & 42 & 74 \\
\hline \multirow[t]{2}{*}{ Total } & 100 & 100 & 100 & 100 & 100 \\
\hline & (205) & (521) & (85) & (322) & (54) \\
\hline \multicolumn{6}{|l|}{ Argumentation role } \\
\hline Origination & 35 & 28 & 18 & 15 & 20 \\
\hline Subject shift & 20 & 21 & 29 & 14 & 4 \\
\hline Reaction/follow-up & 44 & 52 & 53 & 71 & 76 \\
\hline \multirow[t]{3}{*}{ Total } & 99 & 101 & 100 & 100 & 100 \\
\hline & (205) & $(521)$ & $(85)$ & (322) & (54) \\
\hline & \multicolumn{3}{|c|}{ Argumentation role } & & \\
\hline \multirow[t]{2}{*}{ Grammatical Form } & Originate & Shift & Reaction & & \\
\hline & $\%$ & $\%$ & $\%$ & & \\
\hline Question & 89 & 84 & 67 & & \\
\hline Statement & 11 & 16 & 33 & & \\
\hline Total & $\begin{array}{c}100 \\
(290)\end{array}$ & $\begin{array}{c}100 \\
(229)\end{array}$ & $\begin{array}{c}100 \\
(675)\end{array}$ & & \\
\hline
\end{tabular}

Note: $\quad$ Figures in parenthses are column Ns.

were reactive. Finally, within the setting of an OA, we would expect that changes in the subject matter of discussion would be associated with questions, as they typically were, and that statements would be more common in reactive or follow-up behavior. The data show that statements are two-to-three times as common in followups and reactive turns than in nonreactive behavior. In sum, these tables reveal expected patterns of association among the grammatical form, intention, and role variables, and therefore serve to support confidence in the validity of these data.

Data in the crosstabulations of Table 4 test the hypothesis that grammatical form and affective valence interact in the utterances of Justices. Specifically, expressions of positive or negative emotion are predicted to take the declarative mode, indicating certainty, with persuasive consequences, rather than the interrogative, indicating uncertainty. The data show that positive emotional display is infrequent and is usually expressed in a statement. Negative emotion appears in both questions and statements, but is twice as likely to take the declarative mode than non-emotive behavior.

Figure 1 illustrates the distribution across Justices of what may broadly be construed as competitive behavior from seven cases argued in the 1969 and 1970 terms. These seven cases are not intended to be representative of all cases, but were selected because they contained higher frequencies of competitive behavior. Only those Justices with minimal participation in the seven cases are included, and they are ordered on the basis of seniority. The data show (1) acts addressing validity without ex-

Table 4. Grammatical form of verbal affect displays

\begin{tabular}{lccc}
\hline & \multicolumn{3}{c}{ Verbal agreement } \\
\cline { 2 - 4 } Grammatical form & $\begin{array}{c}\text { Agreement } \\
\%\end{array}$ & $\begin{array}{c}\text { None } \\
\%\end{array}$ & $\begin{array}{c}\text { Disagreement } \\
\text { Question }\end{array}$ \\
Statement & 30 & 80 & 54 \\
& 70 & 20 & 46 \\
Total & 100 & 100 & 100 \\
& $(10)$ & $(1005)$ & $(179)$ \\
& & & \\
& & Verbal affect display \\
\cline { 2 - 4 } & Positive & Nons & Negative \\
& $\%$ & $\%$ & $\%$ \\
Question & & & \\
Statement & 14 & 78 & 54 \\
Total & 86 & 22 & 46 \\
& 100 & 100 & 100 \\
& $(7)$ & $(1109)$ & $(78)$ \\
\hline
\end{tabular}

Note: $\quad$ Figures in parentheses are column Ns. 


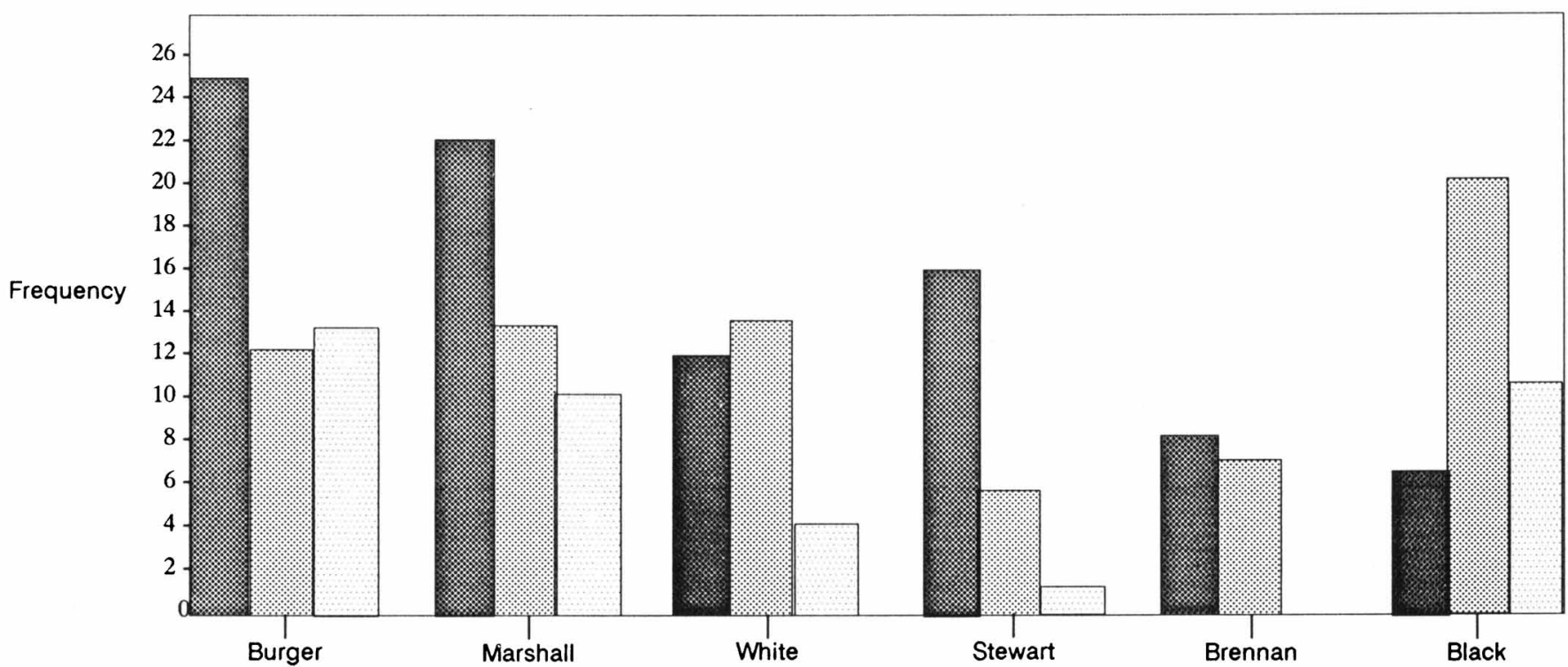

Validity

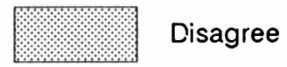

Negative Affect

Figure 1. Competitive and agonistic behavior

Note: Justices are arranged in order by seniority on the court.

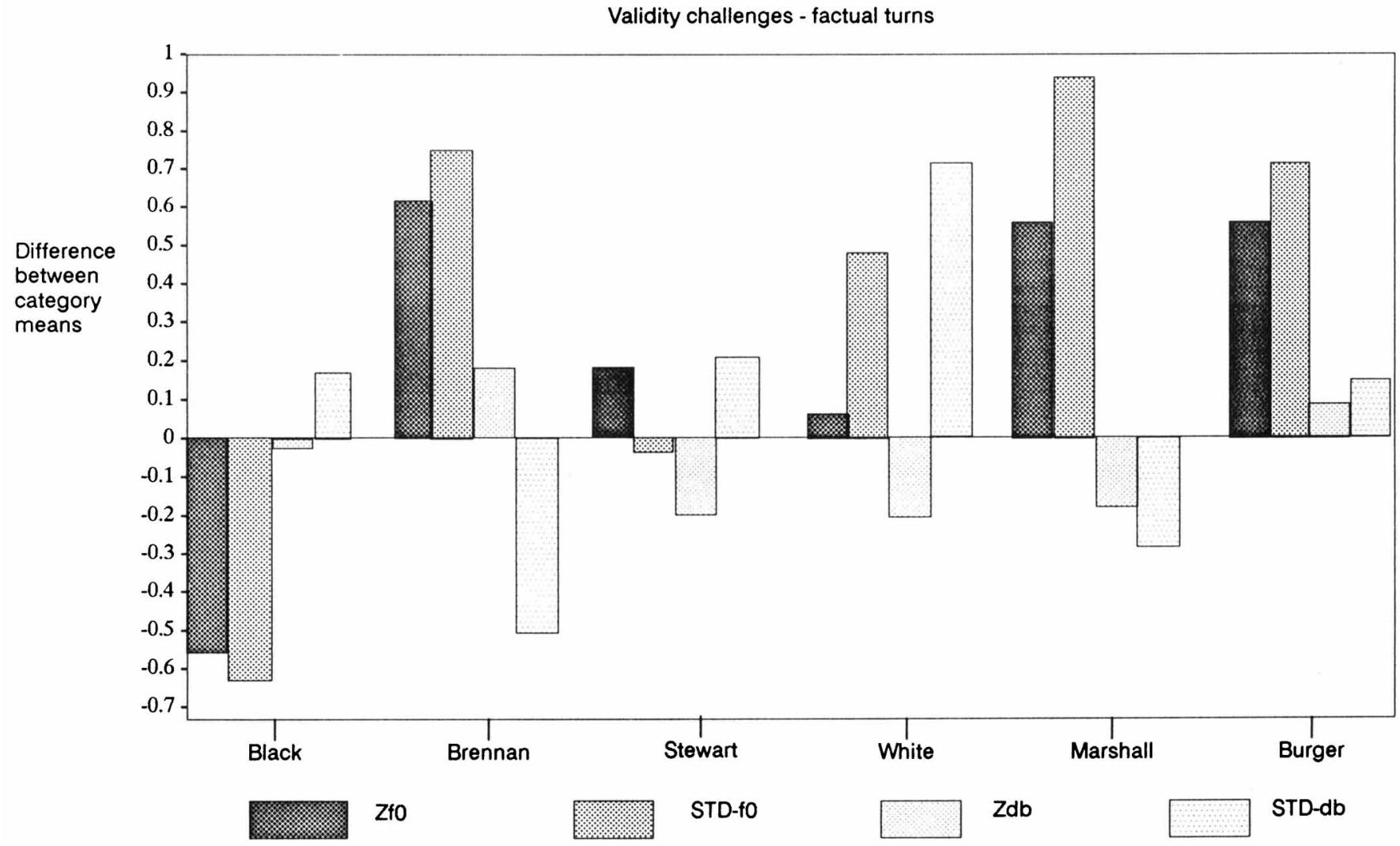

Figure 2. Individual differences in voice quality 
Table 5. Verbal content of Oral Argument in U.S. v. Knox

\section{A. Case summary}

\begin{tabular}{|c|c|c|c|c|c|c|c|}
\hline $\begin{array}{l}\text { Verbal Content } \\
\text { Variable }\end{array}$ & Case Total & Counsel & Court & U.S. Counsel & U.S. Court & Knox Counsel & Knox Court \\
\hline Issues (I) & 71 & 51 & 20 & 10 & 2 & 41 & 18 \\
\hline Bases (B) & 26 & 21 & 5 & 4 & 1 & 17 & 4 \\
\hline Concepts (C) & 53 & 46 & 7 & 11 & 2 & 35 & 5 \\
\hline Roles & 82 & 52 & 30 & 21 & 14 & 31 & 16 \\
\hline Values & 2 & 2 & 0 & 0 & 0 & 2 & 0 \\
\hline Total & 234 & 172 & 62 & 46 & 19 & 126 & 43 \\
\hline + Valence & 3 & 2 & 1 & 0 & 0 & 2 & 1 \\
\hline - Valence & 12 & 11 & 1 & 1 & 0 & 10 & 1 \\
\hline
\end{tabular}

B. Content codes for Justices' questions of the counsel for Knox

$\begin{array}{cc}\text { Variable } & \text { Code Category label } \\ \text { I } & 885 \text { scope of review } \\ \text { I } & 199 \text { miscl-criminal procedure } \\ \text { B } & 1000 \text { Constitution } \\ \text { I } & 853 \text { SC jurisdiction on appeals } \\ \text { I } & 881 \text { statute interpretation } \\ \text { C } & 1 \text { precedent } \\ \text { I } & 853 \text { SC jurisdiction on appeals } \\ \text { C } & 1 \text { precedent } \\ \text { C } & 1 \text { precedent } \\ \text { B } & \text { MISCL } \\ \text { C } & 1 \text { precedent } \\ \text { B } & \text { MISCL } \\ \text { C } & 1 \text { precedent }=\text { Dennis } \\ \text { I } & 869 \text { federal crt. jurisdiction } \\ \text { I } & 177 \text { perjury } \\ \text { I } & 199 \text { miscl-criminal procedure } \\ \text { I } & 177 \text { perjury } \\ \text { I } & 15 \text { retroactivity } \\ \text { B } & 5 A S I \text { th Am self-incrimination } \\ \text { I } & 199 \text { miscl-criminal procedure } \\ \text { I } & 199 \text { miscl-criminal procedure } \\ \text { I } & 199 \text { miscl-criminal procedure } \\ \text { I } & 199 \text { miscl-criminal procedure } \\ \text { I } & 199 \text { miscl-criminal procedure } \\ \text { I } & 199 \text { miscl-criminal procedure } \\ \text { I } & 165 \text { false statements } \\ \text { I } & 199 \text { miscl-criminal procedure } \\ \text { I } & 177 \text { perjury } \\ \text { I } & 165 \text { false statements } \\ \text { I } & 199 \text { miscl-criminal procedure }\end{array}$

Note: These codes are referenced by Side, Turn, Speaker, transcript page and line numbers, etc.

pressing disagreement or negative affect; (2) acts expressing disagreement without negative affect; and (3) all acts displaying negative affect. Inverse rank-order correlations of validity challenges and negative-affect displays with seniority are obvious. Regardless of whether such interesting correlations hold as the database is expanded, they illustrate how these data may be organized for purposes of hypothesis testing. 


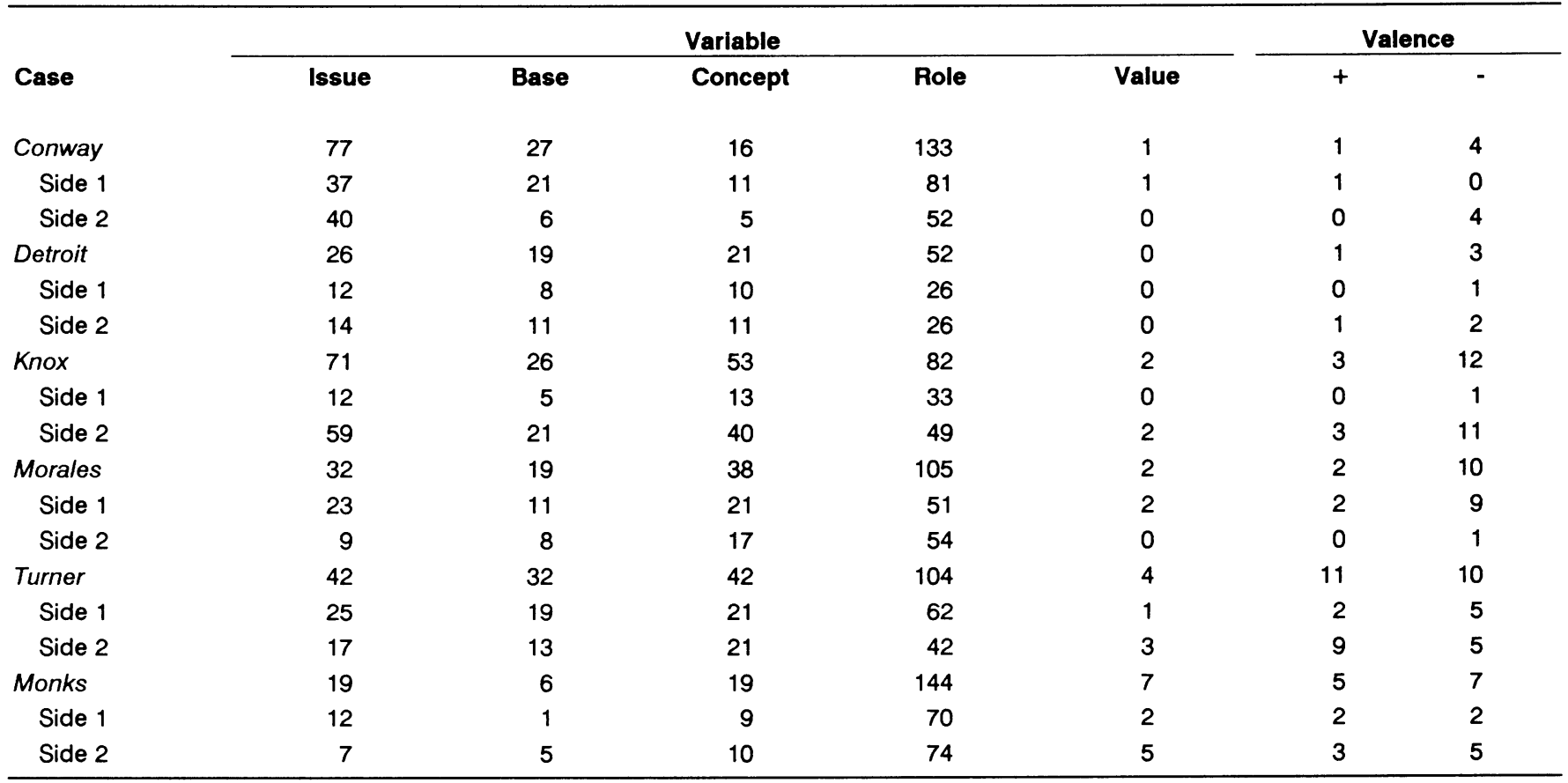

Note: Data are frequency counts for the number of coded observations in each category.

The same cases and turns provided the database for Figure 2. This figure illustrates how voice quality data on arousal may be integrated with observations on other properties of behavior and displayed in aggregate form for individual Justices. These data test the hypothesis relevant to concurrent validity that Justices are more psychophysiologically aroused when they challenge the validity of counsels' arguments than when they ask factual questions. Clearly, we would expect little emotional arousal in questions regarding factual matters, but heightened arousal in competitive behavior. The plotted data are differences between the Justices' mean scores on each variable in turns with validity and factual codes. The data on pitch (labeled Zf0 in the graph) and loudness (labeled $\mathrm{Zdb}$ ) are standardized for each Justice within each case. Leaving Black aside for the moment, pitch was elevated for the other five, and pitch variability was greater for four of the five. Some degree of arousal appears associated with competitive behavior. Black's unique pattern points toward the importance of individual differences and the necessity of individual studies of emotional response patterns.

Table 5 provides data for U.S. v. Knox (396 US 77) that illustrate the results of coding the verbal content of $O A$. The case dealt with the claim of a right, under the Fifth Amendment, to file a false IRS tax form for wagering; Knox lost 6 to 2. The first part of the table provides summary statistics on verbal content codes, broken down by type of actor and side. Comparing the Court's treatment of the opposing sides, there was far more substantive attention to the argument for Knox. Thus, although the frequency of role codes is similar, there were 18 issue codes for Knox compared to 2 for the U.S. Knox's attorney appears to have responded with some emotion. The data show 12 total valence codes, 10 of them negative, for Knox's counsel, compared with 1 for the U.S. attorney. Table 5 also displays a partial list of the actual verbal content codes for the Justices' questions of Knox's counsel. It appears from the issue and base codes that the Court paid little attention to the Fifth Amendment claims and, instead, focused on jurisdictional issues and perjury. Indeed, Douglas's and Black's dissent in the case dealt with the constitutional authority of the IRS to require filing of forms on wagering. Such "key" variables as side, speaker, and turn number allow the verbal content codes to be related to data on form, intention, and affect, at the levels of analysis of turn and Justice, as well as of case. Integrated across the diverse sources and organized sequentially by turn, these data provide rich possibilities for analyzing the sequential process of legal argumentation.

Table 6 presents frequency distributions for verbal content variables, by side, for Knox and five other cases. For instance, 77 references to legal issues were observed in Knox, 37 for appellant counsel's OA, and 40 for appellee counsel's $O A$. These data reveal the variability in $O A$ content. First, the frequency of codes varies widely across cases with relatively few codes for Detroit, Morales, and Monks, but a great many for Knox, Conway, and Turner. The distribution of codes across the content variables is also quite variable. Knox and Conway both show a strong emphasis on legal issues in their OAs, whereas Morales 
reveals more emphasis on legal concepts. Summary data of this form may be joined with other case level data to enable analysis of patterns for OAs as a whole.

\section{Summary}

This paper describes a methodology for analyzing faceto-face oral political communication. The methodology addresses the behavioral appearance of communications, the emotional bases of the behavior, and the substantive content of the message. Because we are studying Supreme Court oral argument, and because cameras are not yet allowed in federal courtrooms, the method is adapted for observation and measurement from a raw data base consisting of words and sound.

Five separate data sets are developed independently and integrated into a general database on OA. The first data set consists of the actual text of the utterances in $\mathrm{OA}$, and it provides the base for qualitative analysis. The second data set is generated by coding behavioral properties of turns for form, argumentation role, intention, and positive/negative affect expression. The third data set is based on patterns in language use and speech behavior, including speech disturbances, speech rate, word selection, and selective word frequencies. It is developed both through manual coding of events in speech and through computer content analysis. The fourth data set consists of acoustical properties of voice quality in speech. The fifth includes observations on the specific subject matter or verbal content of expressions. With the exception of the fifth set, these data are initially developed at the level of the speaking turn and are aggregated from this level to others, such as the Justice, the case, or even an issue area. At the Justice level, the data can be related to archived sources of data on judicial attributes and attitudes. At the case level, the data can be related to diverse data available on cases, including those archived in the NSF Supreme Court Judicial Data Base.

Although defined at the case level to achieve initial research goals, the possibilities for micro level analyses at the level of the phrase or even word are not precluded and, indeed, could be defined to take advantage of the verbal content codes that are defined at a level below the turn. However labor intensive the observation and meas- urement process may be, the quality of observational data offered by these methods promises substantial insights into the operation of small group political decision-making. As the findings may demonstrate, it is possible to have direct, empirical data describing what elites have to say, how they say it, and how they feel about what they say.

Establishing reliability and validity are major challenges for any social science methodology. The wealth of data yielded through observational studies assures ample opportunities to explore concurrent and predictive validity. Reliability is the greater problem, but our approach allows any behavioral observation to be replicated and checked against the original source.

\section{Conclusion}

Discussions of our papers reporting on OA frequently regress to the basic question: "Does OA matter?" From the early and preliminary data reported above, it is apparent that Justices behave as though OA does matter to them. However, perhaps because political scientists do not study or systematically consider OA, the presumption appears to be that it does not matter. Attention focuses on the novelty of observing interaction, rather than on the theoretical and empirical issues at stake. No doubt, if we were studying Congressional committee hearings, the point of discussion and baseline presumption would be the same. However, to many of us watching the Senate Judiciary Committee's "rehearing" of the Clarence Thomas nomination to the Supreme Court, it was obvious that the proceedings mattered to the participants and that the questions and answers were substantively important political behavior. In general, the reasonable presumption should be that face-to-face interactions do matter. Humans tend to make decisions face-to-face; they always have. And, now that the means are available to rigorously observe this behavior, the time has come to study it. The task confronting political scientists is to develop the methods and techniques that will allow us to explore social interactions in decisionmaking groups and how they affect outcomes. We hope this article will contribute to a dialogue on how to study political decision-making through observational research.

\section{Appendix. Reliability.}

Anyone familiar with the type of data we are developing on OA will recognize the difficulty of developing reliable data on the kinds of indicators we discuss. We have implemented a two-phased approach to developing reliable data in these areas. First, through attention to the coding instruments, on the one hand, and rigorous training of coders, on the other, we have sought to achieve accept- able levels of intercoder agreement. Second, a project Principal
Investigator $(\mathrm{PI})$ verifies all codes by checking coder decisions
against the language in the printed transcripts.
Table $\mathrm{A} 1$ presents the results of a test for intercoder agreement.
The results illustrate typical levels of agreement achieved and
problems encountered. The data are from the 225-turn OA in Monks 
Table A1. Intercoder agreement for form and function variables in Monks

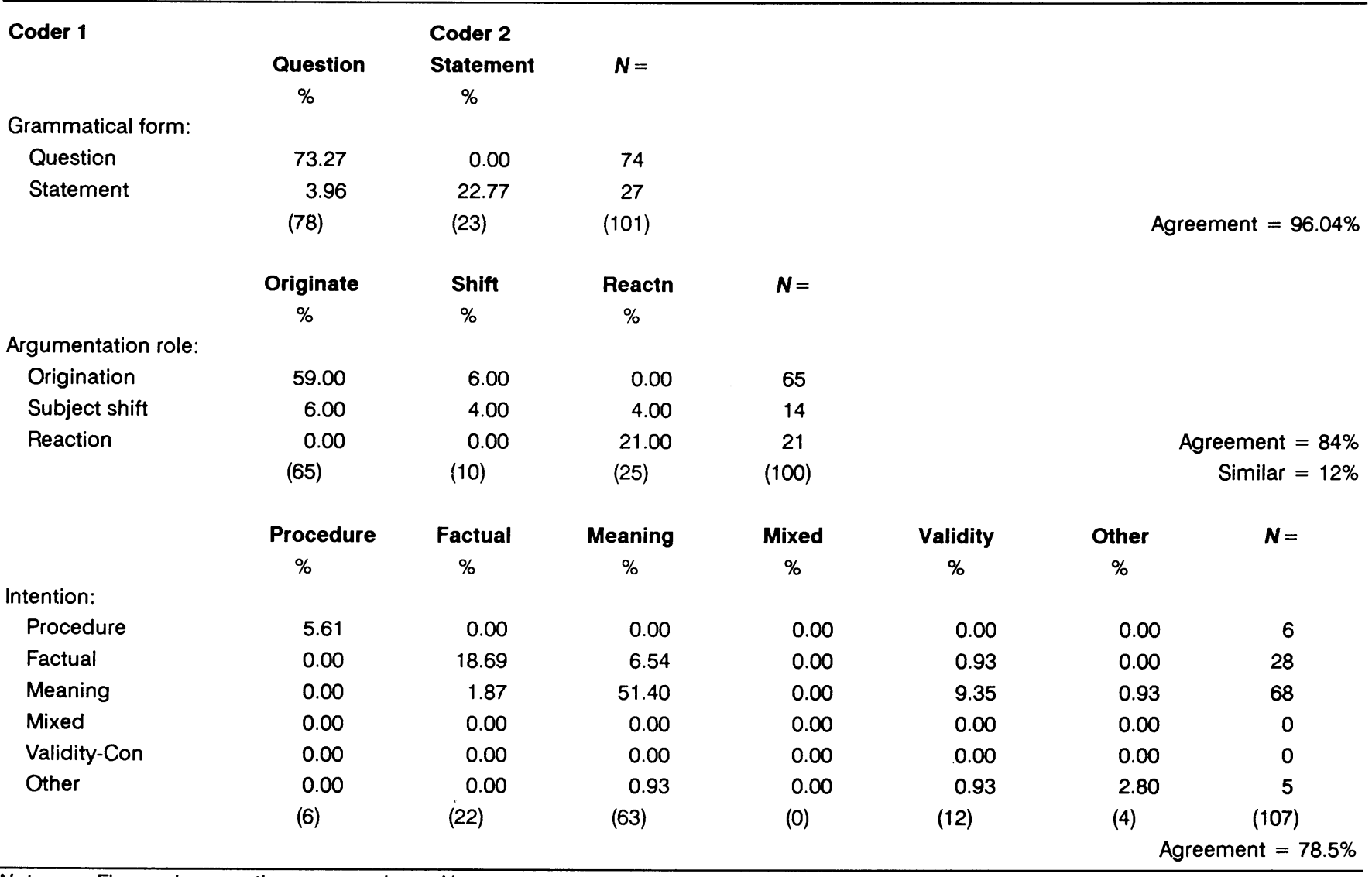

Note: $\quad$ Figures in parentheses are column Ns.

v. New Jersey, which included 107 turns by Justices. Codes for the two coders on each variable are crosstabulated, and the frequencies are calculated as a percentage of the 107 total turns for Justices, to allow sums across categories for total intercoder agreement. These data reveal nearly perfect agreement in coding grammatical form. The categorical distinction is quite clear, and intercoder agreement typically runs about $95 \%$ on this variable.

Agreement is also high for argumentation role. Most clear is the distinction between reactive and nonreactive behavior. In each instance that Coder 1 observed a reaction, Coder 2 also observed a reaction (Coder 2 did observe four more reactions that were regarded as subject shifts by Coder 1). Notably, there were no instances in which the coders disagreed between the origination and reaction categories.

On the variable for intention, which had six possible coding choices, the coders provided identical codes for $78.5 \%$ of the Justices' turns. One source of modest confusion was between the "factual" and "meaning" categories - primarily when Coder 1 observed a "factual" turn, but Coder 2 observed "meaning." Another point of confusion was between "validity" (by Coder 2) and "meaning" (by Coder 1). Although the disagreements for this case are few, these data do illustrate that the difficulties in coding this variable involve the factual/ meaning and meaning/validity discriminations.

It may be obvious from the distributions that Monks was not a particularly contentious $O A$. There were so few codes for disagreement/agreement and for positive/ negative affect that intercoder agreement for these data are nearly perfect. Subsequently, we will report on intercoder agreement based upon 75 cases. Overall, these data illustrate the levels of intercoder agreement that are obtainable from OA materials for these aspects of behavior with well-trained, motivated, intelligent, upper-level undergraduate coders.

Table A2 presents data summarizing intercoder agreement for four of the first OAs to which the verbal content coding instrument was applied. A coding decision is used as the unit of analysis for these data. Coders make decisions to code or not to code the words or sets of words that appear in turns. Thus, one problem of agreement is whether a segment of speech deserves a verbal content code. If so, then a second problem of agreement is what type of code. The greatest source of disagreement among coders is whether or not a speech segment deserves a code. When both coders decide that no code is required, that is an instance of intercoder agreement. When coders decide that a code is required, they tend to agree on the specific variable and category. In this situation, if they differ, it is often on whether to code, for instance, references to freedom of speech, habeas corpus, or double jeopardy under the Issue or Base variables. The role of the PI reviewing their decision is, therefore, essential to the data development process.

If coders used the same variable and closely related categories, their decisions are treated as "very similar" in Table A2. If they used different variables (e.g., Issue and Base), but similar categories (habeas corpus), their decisions are treated as "similar." If they used different codes altogether, or one provided a code where the other did not, their decisions are treated as in "disagreement." Agreement for "no code" decisions was operationalized at the level of the line of text. Because lines with codes occasionally have more than one code, the total $\mathrm{N}$ of coding decisions for cases in Table $\mathrm{A} 2$ is slightly greater than the total lines of text in the transcript.

The data in Table A2 reveal disagreement in slightly less than $20 \%$ of the decisions. This level of disagreement is inflated by the fact that Coder 1 for each case was the same person, where Coder 2 varied, and Coder 1 had an idiosyncratic tendency to overcode. Thus, he coded almost everything that should have been coded, as well as many references that should not have been coded. The actual frequency of identical codes is fairly impressive, given the array of possible codes, and we attribute this to the unambiguous, 
Table A2. Intercoder agreement in verbal content coding

\begin{tabular}{|c|c|c|c|c|c|c|c|c|}
\hline $\begin{array}{l}\text { Decisions of two } \\
\text { coders }\end{array}$ & Frequency & $\%$ & Frequency & $\%$ & Frequency & $\%$ & Frequency & $\%$ \\
\hline \multicolumn{9}{|l|}{ Agreement } \\
\hline No Code & 390 & 53.3 & 515 & 67.1 & 568 & 59.3 & 740 & 67.9 \\
\hline Identical & 162 & 22.1 & 92 & 12.0 & 151 & 15.8 & 140 & 12.8 \\
\hline Very Similar & 28 & 3.8 & 3 & 0.4 & 37 & 3.9 & 16 & 1.5 \\
\hline Similar & 11 & 1.5 & 4 & 0.5 & 23 & 2.4 & 5 & 0.5 \\
\hline Disagreement & 141 & 19.3 & 153 & 19.9 & 179 & 18.7 & 189 & 17.3 \\
\hline Total & 732 & 100.0 & 767 & 100.0 & 958 & 100.0 & 1,090 & 100.0 \\
\hline
\end{tabular}

objective rules governing the coding of the Role, Concept, Base, and Issue variables. There were so few Value codes for these cases that it would be presumptuous to comment on agreement in coding them. Similarly, because the frequency of $+/-$ valence codes was so low, there was extraordinary intercoder agreement, but only regarding the "none" category. Assessment of intercoder agree- ment on the Value variable and on affective valences for all variables will subsequently be analyzed with data aggregated across a substantial set of cases. Where these data do provide a basis for inference, we find that they support the reliability of the verbal content measurement model that we have applied in this research.

\section{Notes}

1. See, for example, the holdings of the Public Affairs Video Archives at Purdue University that range from complete CSpan coverage of the Senate's confirmation process of the Bork nomination to a diverse, comprehensive collection of materials on the Persian Gulf War.

2. Reports of findings on theoretical questions are provided in several papers presented in 1991, including J. N. Schubert et al. (1991a, 1991b), Peterson et al. (1991), Wasby et al. (1991), and G. Schubert et al. (1991a, 1991b).

\section{References}

Baken, R. J. (1987). Clinical Measurement of Speech and Voice. Boston, Mass.: Little, Brown and Company.

Bales, Robert F. (1950). Interaction Process Analysis. Ann Arbor: University Microfilms.

Barber, J. D. (1966). Power in Committees: An Experimental Study in the Government Process. Chicago: Rand McNally.

Barner-Barry, C. (1986). "An Introduction to Nonparticipant Observational Research Techniques." Politics and the Life Sciences 5:139-146.

Brenner, S. (1980). "Fluidity on the United States Supreme Court: A Reexamination." American Journal of Political Science 24:526535.

Brenner, S. and H. J. Spaeth (1986). "Issue Specialization in Majority Opinion Assignment on the Burger Court." Western Political Quarterly 39:520-527.

Chapper, J. (1983). "Oral Argument and Expediting Appeals." Journal of Legal Reform 16:517-526.

Dorff, R. H. and J. Steiner (1981). "Political Decision Making in Face-to-Face Groups: Theory, Methods, and an Empirical Application in Switzerland." American Political Science Review 75:368-380

Fenno, R. F. (1986). "Observation, Context, and Sequence in the Study of Politics." American Political Science Review 80:3-15.

Frank, R. S. (1977). "Nonverbal and Paralinguistic Analysis of Political Behavior: The McGovern-Humphrey California Primary Debate." In M. Hermann, ed. A Psychological Examination of
Political Leaders. New York: Free Press.

Goldman, S. (1969). "Backgrounds, Attitudes, and the Voting Behavior of Judges: A Comment on Joel Grossman's Social Background and Judicial Decisions." Journal of Politics 31:214-222.

Gray, J. A. (1982). The Neuropsychology of Anxiety: An Enquiry into the Functions of the Septo-Hippocampal System. New York: Oxford University Press.

Harlan, J. M., Jr. (1955). "The Role of Oral Argument." Cornell Law Review 41:6.

Hermann, M. (1977). "Verbal Behavior of Negotiators in Periods of High and Low Stress: The 1965-66 New York City Transit Negotiations." In M. Hermann, ed. A Psychological Examination of Political Leaders. New York: Free Press.

Howard, J. W. (1968). "On the Fluidity of Judicial Choice." American Political Science Review 62:43-56.

- (1981). Courts of Appeals in the Federal Judicial System. Princeton, NJ: Princeton University Press.

Marcus, G. E. (1988). "The Structure of Emotional Responses: 1984 Presidential Candidates." American Political Science Review 82:737-762.

Mazur, A. and M. Cataldo (1989). "Dominance and Deference in Conversation." Journal of Social and Biological Structures 12:87-99.

McFeeley, N. D. and R. J. Ault (1979). "Supreme Court Oral Argument." Jurimetrics Journal 20:52-84.

Murphy, W. F. (1966). "Courts as Small Groups." Harvard Law Review 79:1565-1572.

Nardulli, P. F., R. B. Flemming, and J. Eisenstein (1984). "Unraveling the Complexities of Decision Making in Face-to-Face Groups: A Contextual Analysis of Plea-Bargained Sentences." American Political Science Review 78:912-927.

New York Times (1989). "Transcript of Arguments Before High Court on Abortion Case." B12 (April 27).

Peterson, S. A., S. Wasby, G. Schubert, and J. Schubert (1991). "Patterns in Supreme Court Oral Argument." NSF Oral Argument Project Paper No. 6. Paper presented at the meeting of Law and Society Association, Amsterdam.

Scherer, K. R. (1986). "Vocal Affect Expression." Psychological Bulletin 99:143-165.

Schubert, G. (1974). The Judicial Mind Revisited. New York: Oxford University Press. 
(1985). Political Culture and Judicial Behavior, Volume II. Lanham, MD: University Press of America.

Schubert, G. and R. D. Masters, eds. (1991). Primate Politics. Carbondale, III.: Southern Illinois University Press.

Schubert, G., S. Peterson, S. Wasby, and J. Schubert (1991a). "Justices' Participation in Supreme Court Oral Argument." NSF Oral Argument Project Paper No. 3. Paper presented to the annual meeting of the Western Political Science Association, Seattle.

- (1991b). "Patterns of Oral Argument and Case Outcomes in the Supreme Court: 1969 and 1970 Terms." NSF Oral Argument Project Paper No. 9. Paper presented at the annual meeting of the American Political Science Association, Washington.

Schubert, J. N. (1983). "Ethological Methods for Observing Small Group Political Decision Making." Politics and the Life Sciences 2:3-38.

(1987). "Judicial Behavior in Oral Argument: A Psycholinguistic Analysis." Paper presented at the annual meeting of the Midwest Political Science Association, Chicago.

- (1988). "Politics under the Microscope: Observational Methods in Political Research." International Political Science Review 9:335-355.

- (1990). "Oral Argument and Size of Majority in Supreme Court Decision Making." Paper presented at the annual meeting of the New York State Political Science Association, Albany.

Schubert, J. N., S. Peterson, S. Wasby, and G. Schubert (1991a). "Descensus and Unanimity in Supreme Court Decision Making." NSF Oral Argument Project Paper No. 9. Paper presented at the World Congress of the International Political Science Association, Buenos Aires.

(1991b). "Judicial Involvement and Leadership in Oral Argument." NSF Oral Argument Project Paper No. 7. Paper presented at the meeting of the International Society for Political Psychology, Helsinki.

Schwartz, B. (1985). The Unpublished Opinions of the Warren Court.
New York: Oxford University Press.

(1988). The Unpublished Opinions of the Burger Court. New York: Oxford University Press.

Shapiro, S. M. (1984). "Oral Argument in the Supreme Court of the United States." Catholic University Law Review 33:529-553.

Siegman, A. W. (1978). "The Tell-Tale Voice: Nonverbal Messages of Verbal Communication." In A. W. Siegman and S. Feldstein, eds. Nonverbal Behavior and Communication. New York: John Wiley and Sons.

Spaeth, H. J. (1991). United States Supreme Court Judicial Data Base, 1953-1989 Terms. Ann Arbor, Ml: Inter-University Consortium for Political and Social Research.

Ulmer, S. S. (1981). "Leadership and Group Structure." In S. Sidney Ulmer (ed.), Courts, Law and Judicial Processes. New York: Free Press.

Wahlke, J.C. (1979). "Pre-Behavioralism in Political Science." American Political Science Review 73:9-31.

Wasby, S. L. (1981). "Oral Argument in the Ninth Circuit." Golden Gate Law Review 11:21-79.

- (1982). "The Function and Importance of Appellate Oral Argument." Judicature 65:340-353.

Wasby, S. L., A. A. D'Amato, and R. Metrailer (1976). "The Functions of Oral Argument in the U.S. Supreme Court." Quarterly Journal of Speech 62:410-422.

Wasby, S. L., S. Peterson, G. Schubert, and J. Schubert (1991). "The Supreme Court's Use of Per Curiam Dispositions: The Connection to Oral Argument." NSF Oral Argument Project Paper No. 5. Paper presented at the annual meeting of the Midwest Political Science Association, Chicago.

Watson, G. and J. Stookey (1988). "Supreme Court Confirmation Hearings: A View from the Senate." Judicature 71:186-196.

Watts, M. W. (1981). "Individual Differences in Skin Conductance Response to Vicariously Modeled Violence and Pathos." New Directions for Methodology of Social and Behavioral Science 7:81-87. 


\section{"I want summaries of books, articles and papers on science and technology studies."}

\section{Current Literature on Science of Science could be part of your solution.}

CLOSS is a monthly abstracting journal. It will enable you to track the literature on science and technology policies, especially in the newly industrialising and other developing countries. Over 100 journals, international and regional, are regularly scanned, together with the book and monograph lists of many publishers and research institutes across the world.

Features: book reviews; summaries of other books, articles and working papers; some international news and notes; and conference reports.

Editors: edited at the National Institute for Science, Technology and Development Studies (NISTADS) in New Delhi, India, under its director, Dr Ashok Jain. Dr Jain has worked in MITI in Japan. NISTADS has around 60 professional staff.

Coverage: history and philosophy of science; technological and social change; sociology of science; international politics of S\&T; mathematical modelling for S\&T studies; R\&D management; training; resource planning and utilisation.

\section{Sample entry from CLOSS}

\begin{tabular}{|c|c|}
\hline Category $\rightarrow$ & $\begin{array}{l}\text { BOO SCIENCE \& TECHNOLOGY POLICY } \\
\text { RESOURCES }\end{array}$ \\
\hline Subcategory $\rightarrow$ & HUMAN RESOURCES FOR S\&T \\
\hline $\begin{array}{l}\text { Author } \rightarrow \\
\text { and title } \rightarrow \\
\text { Source } \rightarrow\end{array}$ & $\begin{array}{l}\text { MAJCHRZ, A, Effects of CAD on the jobs of } \\
\text { crafters and engineers: a quantitative analysis, } \\
\text { Intermational Joumal of Man-Machine Studies, } \\
\text { 1990, 32, 245-282. }\end{array}$ \\
\hline Abstract $\quad \rightarrow$ & $\begin{array}{l}\text { Job characteristics and performance data for users } \\
\text { and non-users of a CAD for mechanical design } \\
\text { were quantitatively compared. Results indicated that, } \\
\text { for engineers, CAD users experienced more inter- } \\
\text { dependence on their job while, for crafters, CAD users } \\
\text { experienced less discretion, creativity, and teamwork. } \\
\text { These differences between users and non-users were not } \\
\text { related to individual performance. Implications for } \\
\text { practitioners implementing CAD and researchers studying } \\
\text { technological change are drawn. }\end{array}$ \\
\hline Author affiliation $\rightarrow$ & $\begin{array}{l}\text { Dept of Human Factors } \\
\text { University of Southern California } \\
\text { Los Angeles, CA } 90089-0021 \text {, USA }\end{array}$ \\
\hline
\end{tabular}

\section{Subscription information}

Published monthly, usually 40 pages/issue $(215 \mathrm{~mm}$ x $275 \mathrm{~mm})$. Multi-year subscriptions cost exact multiples of one-year price. Orders within India to CLOSS, Publications and Information Directorate, K S Krishnan Marg, New Delhi 110012. ISSN 0379-4504. Prices for one-year subscriptions starting in 1992, volume 20:

Normal price: $£ 59$ or US\$108

Third world or Eastern Europe: $£ 39$ or US $\$ 68$

Personal or student price: $£ 28$ or US48

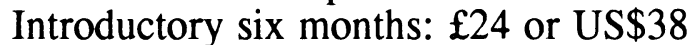

Beech Tree Publishing

10 Watford Close, Guildford

Surrey GU1 2EP, UK

Phone/fax +44(0)483 67497 